\title{
AN EXPERIMENTAL INVESTIGATION ON THE PERFORMANCE, COMBUSTION AND EMISSION CHARACTERISTICS OF CI DIESEL ENGINE AT VARIOUS COMPRESSION RATIO WITH DIFFERENT ETHANOL-BIODIESEL BLENDS ${ }^{1}$ Subramanyam Pavuluri, ${ }^{2}$ Dr.B.Sidda Reddy, ${ }^{3}$ Dr.B.Durga Prasad

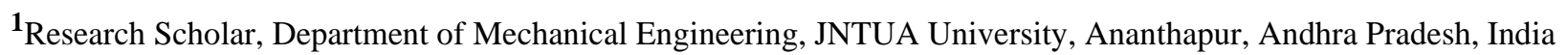 \\ ${ }^{\mathbf{2}}$ Associate Professor, School of Mechanical Engineering, RGMCET, Nandyala, Andhra Pradesh, India \\ ${ }^{3}$ Professor, Department of Mechanical Engineering, JNTUA University, Ananthapur, Andhra Pradesh, India
}

Corresponding author email id: subramanyampavuluri@gmail.com

Abstract: In the present scenario of increased industrialization and transportation in the world leads to increased consumption of fossil fuels which in turns leads to depletion of fossil fuels at a faster rate. Fossil fuels combustion is the dominant source for greenhouse gases and global warming. In view of energy crisis raised in 1970's and environmental concern, many researches are directed towards search of alternative fuels which can replace use of fossil fuels there by reducing pollution. In developing countries like India which is agriculture land the promising bio-fuels are biodiesel and ethanol which are produced from various renewable feedstock like sugarcane, corn etc. and they are also less hazardous to environment because of lower emission property. Ethanol blends results in decreased emissions of hydrocarbon (HC), carbon monoxide (CO) and particulates matter but increase in nitrogen oxides (NOx). Addition of ethanol leads to reduction of biodiesel viscosity. This paper represents variations in the engine parameters like performance, combustion and emission of single cylinder four stroke CI diesel engine by using various compression ratios such as 17.5:1, 18.5:1 and 19.5:1. Experimental research has been conducted with four proportions ethanol, namely E10, E20, E30 and E40. Ethanol-biodiesel mixture mixed with $2 \%$ emulsifier $1 \%$ diethyl carbonate and $1 \%$ ethyl acetate to maintain similarity and to avoid phase separation. Ethanol subjected to high compression ratio has been used to increase brake thermal efficiency (BTE). Increased compression ratio also improves the combustion and performance of the diesel engine.

Keywords: Compression Ratio (CR), CI Diesel Engine, Ethanol, Biodiesel, Performance, Combustion, Emissions and Emulsifier; 


\section{NOMENCLATURE}

\begin{tabular}{|c|l|c|l|}
\hline AFR & Air Fuel Ratio & $\mathrm{H}$ & Hydrogen \\
\hline BMEP & Break Mean Effective Pressure & $\mathrm{HC}$ & Hydro Carbon \\
\hline BP & Break Power & $\mathrm{H} / \mathrm{C}$ & Hydro/Carbon \\
\hline BTE & Break Thermal Efficiency & $\mathrm{HRR}$ & Heat Release Rate \\
\hline $\mathrm{B} 20$ & $20 \%$ level of biodiesel & $\mathrm{IP}$ & Indicated Power \\
\hline $\mathrm{C}$ & Carbon & $\mathrm{ITE}$ & Indicated Thermal Efficiency \\
\hline $\mathrm{CO}$ & Carbon Monoxide & $\mathrm{IMEP}$ & Indicated Mean Effective Pressure \\
\hline $\mathrm{CO}_{2}$ & Carbon Dioxide & $\mathrm{kW}$ & Kilo Watt \\
\hline $\mathrm{CI}$ & Compression Ignition & $\mathrm{MEP}$ & Mean Effective Pressure \\
\hline $\mathrm{CN}$ & Cetane Number & $\mathrm{NO}$ & Nitrogen Oxides \\
\hline E10 & 10 percent ethanol-blended fuel & $\mathrm{O}$ & Oxygen \\
\hline E20 & 20 percent ethanol-blended fuel & $\mathrm{SFC}$ & Specific Fuel Consumption \\
\hline E30 & 30 percent ethanol-blended fuel & $\mathrm{TDC}$ & Top Dead Centre \\
\hline E40 & 40 percent ethanol-blended fuel & VE & Volumetric Efficiency \\
\hline FP & Frictional Power & rpm & Revolution Per Minute \\
\hline
\end{tabular}

\section{INTRODUCTION}

Indian oil imports account for nearly 130 billion \$ every year which accounts for nearly $73 \%$ of the overall usage. This largely import dependent product critically effects our growing economy since its price fluctuates due to several factors such as political and social scenarios in the exporting countries. Emerging third world countries such as China and developed countries such as the United States and most of the western European countries survive on the same sources. While this skewed global supply-demand economics is creating a continuous increase in the oil prices, the rural Indian setting which is developing at a slower rate than most of the metropolitan areas is being worst hit due to the increased prices. Several schemes have been initiated by the Indian government to use renewable fuels obtained from biological wastes to minimize the dependency of foreign oil. Nearly all the production crops in India have a crop to residue ratio of around $35 \%$, implying that nearly $65 \%$ of the crops are available for renewable energy production. Substantial researches are conducted on the usage of biodiesel in the engines, but only $20 \%$ blends (B20) are currently suitable with the current diesel engine designs due to efficiency, durability and emissions issues.

Finding an alternative fuel like methanol, butanol and ethanol is directly benefit for industries, automobiles, farmers and it helps to prevent the issues like greenhouse gas effects. Indeveloping countries like India bio-fuels are economically less expensive than other fossil fuels. Therefore, 
it provides a scope for research work. There are two types of ethanol used in automotive application, one is anhydrous ethanol and the other is hydrous ethanol of which anhydrous ethanol contains a maximum of $0.7 \%$ water on weight basis and hydrous ethanol contains up to $7.4 \%$ of water on weight basis when measured at $20^{\circ} \mathrm{C}$. Hydrous ethanol emits less $\mathrm{CO}_{2}$ compared to biodiesel mass anhydrous [1].

The purpose of this paper is an attempt made to review the previous studies to look into future possibilities of various parameters. This part of the literature survey summarizes the collective information about the Ethanol and other various alternative fuels, combustion, performance, emission in CI Diesel Engine using ethanol in biodiesel and other fuels applications in CI Diesel engine. The reviewed literatures are presented under the following collection of necessary information.

Adding solvents like $2 \%$ emulsifier agent prevents the separation and ensure the similarity. The increased compression ratio has a similar effect as raising the inlet air temperature which results in gradual increase in the intake pressure. The compression ratio modifications effects ignition timing, final temperature and pressure at the end of the compression process [2]. Compression ratio is raised up to 19.5:1 with the help of higher latent heat of vaporization, higher auto ignition temperature which improves of the efficiency of the engine [3]. The mean BTE of engine is increased more than $33 \%$, when the compression ratio is raised gradually from 18 to 20 . By increasing the $\mathrm{CR}$ up to the maximum value which results in improvement of the effective pressure by using hydrous ethanol, while reduction of Mean Effective Pressure (MEP) and Break Thermal Efficiency (BTE) occurs by increasing compression ratio [4]. Increased CR leads to high cylinder temperature which causes faster evaporation of ethanol blends resulting in improvement of the combustion [5].

Based on previous researches and on reviews, the alternative energy fuels were found to be natural gas, alcohol, dimethyl ether and biodiesel. In developing countries like India which is agriculture land, ethanol and biodiesel are the promising alternative fuels which are produced from agriculture feedstock with low cost. It is a highly oxygenated fuel extracted from vegetable edible oils like sunflower, soya bean, palm, rapeseed, peanut etc. produced by process of 
transesterification. The high cetane number of biodiesel than diesel improves it combustion performance. The other additive advantages of biodiesel are low emission levels, increased lubricity, better combustion efficiency, easy biodegradability and low toxicity level. Vegetable oils are highly viscous and low heating value so it cannot be used directly and also increases carbon deposits [6]. To decrease emission rate and viscosity additives are used [7]. It is stated that nonlinear decrease in viscosity occurs by increasing alcohol contents. Addition of ethanol to biodiesel results in various changes in physical and chemical properties of biodiesel fuel [8]. The properties of various fuels are shown in Table.1

Table.1 Properties of various Fuels [7]

\begin{tabular}{|l|c|c|c|}
\hline \multicolumn{1}{|c|}{ PROPERTIES } & DIESEL & BIODIESEL & ETHANOL \\
\hline Purity $(\%, \mathrm{v} / \mathrm{v})$ & - & - & 99.5 \\
\hline Density at $15^{\circ} \mathrm{C}(\mathrm{kg} / \mathrm{m} 3)$ & 842 & 883.5 & 792 \\
\hline Kinematic viscosity at $40^{0} \mathrm{C}(\mathrm{cSt})$ & 3 & 4.19 & 1.13 \\
\hline Gross heating value $(\mathrm{MJ} / \mathrm{kg})$ & 45.77 & 40.19 & 29.67 \\
\hline Lower heating value $(\mathrm{MJ} / \mathrm{kg})$ & 42.93 & 37.64 & 26.84 \\
\hline $\mathrm{C}(\mathrm{wt} \%)$ & 86.74 & 77.08 & 52.14 \\
\hline $\mathrm{H}(\mathrm{wt} \%)$ & 13.26 & 11.91 & 13.13 \\
\hline $\mathrm{O}(\mathrm{wt} \%)$ & 0 & 11 & 34.73 \\
\hline Water content $(\mathrm{mg} / \mathrm{kg})$ & 41.7 & 352.1 & 2024 \\
\hline Molecular weight $(\mathrm{kg} / \mathrm{kmol})$ & 208.2 & 291.26 & 46.07 \\
\hline Boiling point $\left({ }^{\circ} \mathrm{C}\right)$ & $149-385$ & $190-340$ & 78.37 \\
\hline Freezing point $\left({ }^{\circ} \mathrm{C}\right)$ & - & - & -114.1 \\
\hline Stoichiometric fuel/air ratio & - & 353.56 & 943.78 \\
\hline Cloud Point $\left({ }^{\circ} \mathrm{C}\right)$ & -4.3 & 1.9 & - \\
\hline Pour Point $\left({ }^{\circ} \mathrm{C}\right)$ & -21 & 0 & - \\
\hline Cetane number $(\mathrm{CN})$ & 52.65 & 52.48 & 12 \\
\hline
\end{tabular}




\section{EXPERIMENTAL SETUP AND METHODOLOGY}

The schematic diagram of the experimental setup is shown in Fig.1 and Photograph of Experimental Setup of Test Engine is shown in Fig.2. In this experimental study, a Kirloskar DM10 Vertical Single Cylinder, Water-Cooled, Four Stroke Cycle, Compression Ignition Diesel Engine model is used. The engine develops maximum power of $10 \mathrm{~kW}$ at rated speed of 1500 rpm and is directly coupled with FTACS-1 4.8 model water cooled Eddy Current dynamometer.

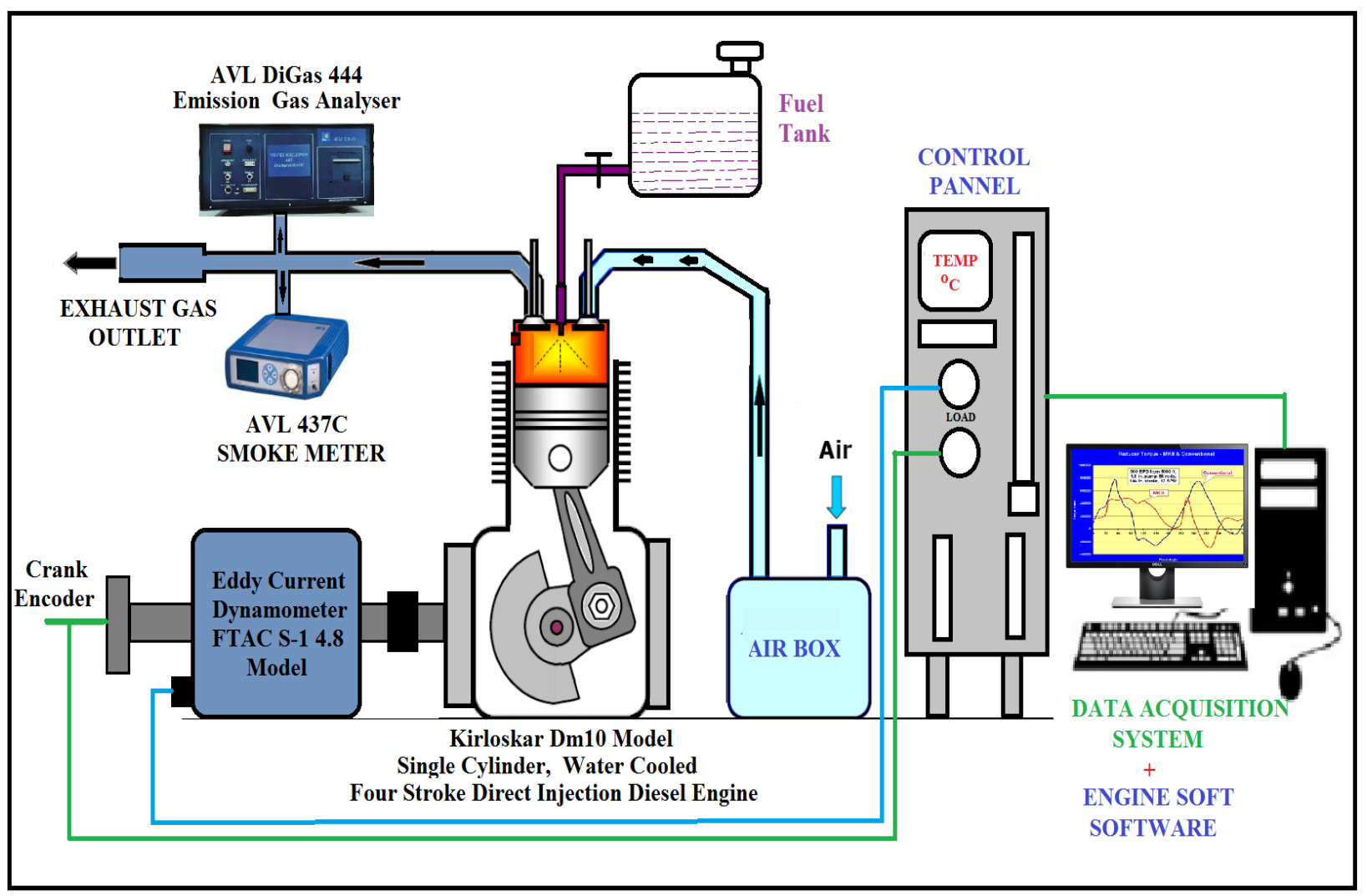

Fig.1. Schematic Diagram of Engine Setup

The setup consists of air box, manometer, fuel tank, fuel measurements unit, load, speed, temperature indicator, rotameter and calorimeter. This setup enables the study of engine performance for Indicated Power (IP), Brake Power (BP), Frictional Power (FP), Indicated Mean Effective Pressure (IMEP), Break Mean Effective Pressure (BMEP), Indicated Thermal Efficiency (ITE), Brake Thermal Efficiency (BTE), Specific Fuel Consumption (SFC), Volumetric Efficiency (VE) and Air Fuel Ratio (AFR). The setup is also needed for analyzing and interfacing air flow, fuel flow, speed, temperature and load measurements. 
The setup is instrumented for measurements of combustion pressure and crank angle. IC engine performance analysis software package named "Engine Soft" provided for online performance and combustion evaluation. The signals are interfaced with computer system through engine indicator for $\mathrm{P}-\theta$ and $\mathrm{P}-\mathrm{V}$ diagrams. $\mathrm{PCB}$ a piezoelectric pressure transducer is used for recording the cylinder pressure for 20 consecutive cycles for variable combustion studies. The experiments are conducted by using various proportions of ethanol and biodiesel blends like E10, E20, E30 and E40 under various compression ratios such as 17.5:1, 18.5:1 and 19.5:1 and the injection pressure used upto 255 bars. The compression ratio is varied by altering the dimensions of the piston bowl by keeping the constant standard stroke volume.

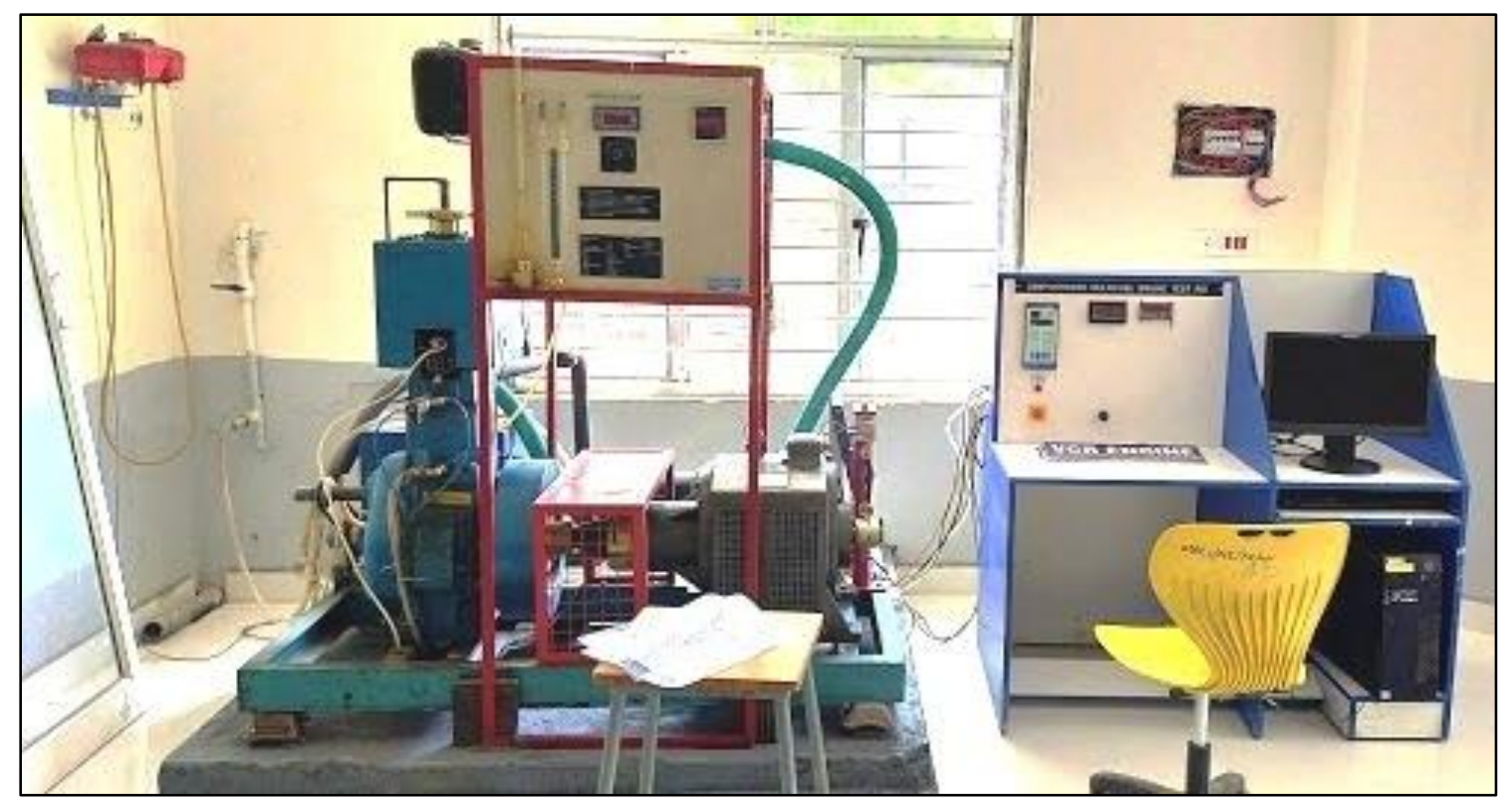

Fig.2. Photograph of Experimental Setup of Test Engine

The initial arrangements of the system are properly checked and test fuel is filled in the fuel tank. The engine is operated at different loads like Zero load, $2 \mathrm{Kg}, 4 \mathrm{Kg}, 6 \mathrm{Kg}, 8 \mathrm{Kg}, 10 \mathrm{Kg}, 12 \mathrm{Kg}$, $14 \mathrm{Kg}, 16 \mathrm{Kg}$ and $18 \mathrm{Kg}$. For each load, fuel-flow, air-flow, temperatures at water inlet and exhaust, Rota meters values are observed and tabulated. AVL 437C smoke analyzer is used are measuring smoke level of the engine and AVL Di Gas 444 gas analyzer is used for measuring the values of exhaust gases like $\mathrm{CO}, \mathrm{HC}, \mathrm{CO}_{2}, \mathrm{NOx}$ and $\mathrm{O}_{2}$. The above values are tabulated for different compression ratios and the same procedure and method is repeated for every different ethanol blends ratio. For every ethanol blend performance and emission values are tabulated and compared with each other. The resulted findings are represented as graphs. 
The Technical Specifications of the Test Engine are represented in Table .2

Table.2 Technical Specifications of the Test Engine

\begin{tabular}{|l|c|c|}
\hline \multicolumn{3}{|c|}{ TECHNICAL SPECIFICATION } \\
\hline Engine make & \multicolumn{2}{|c|}{ Kirloskar Oil engine Limited } \\
\hline Engine Model Type & \multicolumn{2}{|c|}{$\begin{array}{r}\text { Vertical Single Cylinder, Water- } \\
\text { Cooled, four Stroke Cycle, } \\
\text { Compression Ignition Diesel Engine }\end{array}$} \\
\hline No. of Cylinders & - & 1 \\
\hline Bore x Stroke & $(\mathrm{mm})$ & 102 X 116 \\
\hline Cubic Capacity & $(\mathrm{Ltr})$ & 0.948 \\
\hline Compression Ratio & - & $17.5: 1$ \\
\hline Rated Output & $\mathrm{kW}(\mathrm{hp})$ & $7.4(10)$ \\
\hline Rated Speed & $\mathrm{rpm}$ & 1500 \\
\hline Torque at Full Load (Crank shaft Drive) & $\mathrm{kN}-\mathrm{m}(\mathrm{kg}-\mathrm{m})$ & $0.048(4.775)$ \\
\hline Crank Shaft Center Height & $(\mathrm{mm})$ & 203 \\
\hline Specific Fuel Consumption (SFC) & $(\mathrm{gm} / \mathrm{hp}-\mathrm{hr})$ & $1855 \%$ \\
\hline
\end{tabular}

\section{RESULT AND DISCUSSION}

\subsection{PERFORMANCE}

\subsubsection{Impact on Brake Thermal Efficiency (BTE)}

The effect of Ethanol and Biodiesel blends on Break Thermal Efficiency with Break Power at various compression ratios are represented in the Fig.3. Brake thermal efficiency is heat engine brake power, which helps in evaluating how engine converts fuel heat energy into mechanical energy. Incomplete combustion occurs with higher ethanol proportion at low compression ratio, due to longer ignition delay. Applying increased load for same proportion of ethanol results in increased BTE. But increased ethanol proportion leads to decreased BTE because ethanol is having low calorific value, so to generate same power additional fuel is required. By increasing $\mathrm{CR}$ and engine load results in decreased ignition delay and combustion period of ethanol. Rich mixture at high compression ratio of 19.5 and high engine load subjected to high combustion temperature increases oxygen kinetics in ethanol leading to increased break thermal efficiency (BTE). Increasing compression ratio improves power generation. 
It's clearly observed that above $40 \%$ ethanol blend leads to abnormal combustion caused by longer ignition delay which decreases the speed of the engine [9]. High compression ratio of 19.5:1 decreases Break thermal efficiency (BTE) of neat biodiesel and E10 by $20 \%$ and $10 \%$ respectively whereas Break thermal efficiency (BTE) of E20, E30 and E40 increases by 15\%, $20 \%$ and $35 \%$ respectively.
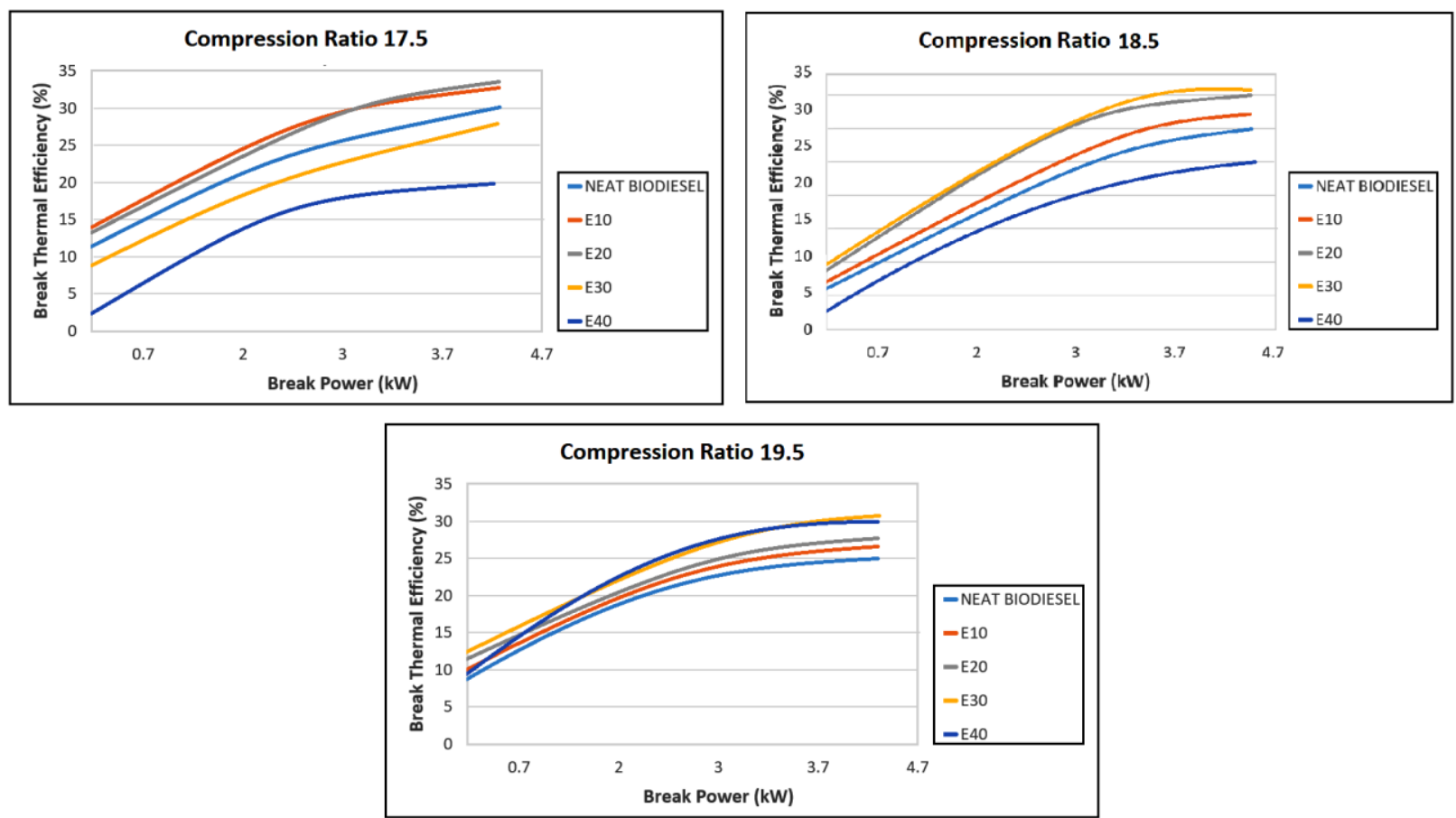

Fig.3. Comparison of Break Thermal Efficiency with Break Power at different CR

\subsection{COMBUSTION}

\subsubsection{Impact on Engine Cylinder Pressure}

The combustion is rapid chemical reaction of substance with oxygen involving heat and light production. The process of combustion is partially premixed and diffusive with major part occurring at premixed state due to raised CR. The identification of complex mechanisms of combustion is difficult and it depends on type of fuel, variables of engine design like compression ratio, air-fuel ratio, fuel injection timing, intake pressure (intake manifold pressure), temperature, combustion chamber deposits, spark timing, engine load, power output, engine speed, exhaust back pressure, valve overlap, and intake manifold pressure. Fig.4. indicates change in cylinder pressure with various compression ratios by using various ethanol blends which are represented below. 
During the compression stroke, at higher temperature better mixture occurs by increasing compression ratio. Engine cylinder pressure is also raised due to increased compression ratio. This results in reduced ignition delay and at TDC the combustion occurs. At this time the ethanol blend reaction is much faster and cause engine cylinder pressure is increase rapidly. The point where biodiesel get ignited, ethanol undergoes evaporation due to low boiling point.
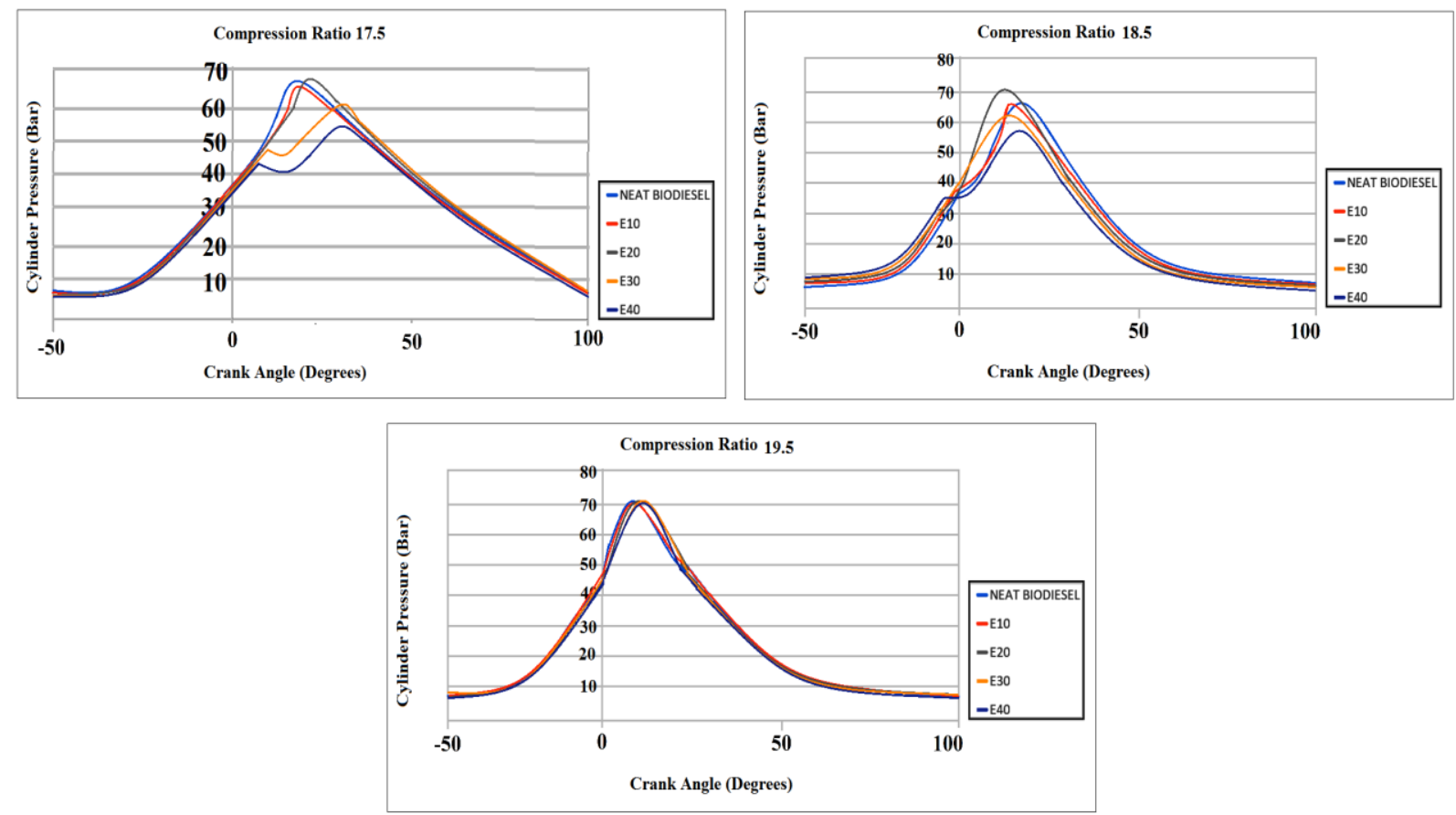

Fig.4. Comparison of Cylinder Pressure with Crank Angle at various CR

This results in ethanol mixture burns rapidly than biodiesel. Unbalanced operation is found with increased ethanol percentage. At high compression ratio, ethanol also meets same pressure as compared to diesel. While increasing compression ratio upto 19.5 and higher loads, E10, E20, E30 and E40 shows peak pressure of 71.42, 71.55, 71.55 and 70.09 bar respectively.

\subsubsection{Impact on Heat Release Rate (HRR)}

The total heat release rate (HRR) for various CR at different percentages of ethanol-biodiesel blends represented in Fig.5. Ignition delay period increases by increasing the proportion of ethanol. The lower cetane point of ethanol helps to evaporate the mixture faster comparatively than the neat biodiesel evaporation which is applied to auto-ignite the mixture quickly. During the early phase of peak combustion period, more fuel mixture is burned as compared to biodiesel blend. 
It observed that at compression ratios of 19.5 with the various ethanol blends Neat Biodiesel, E10, E20, E30 and E40 having peak total heat release rate (HRR) is 44.65, 52.64, 81.44, 81.24 and 88.19 respectively. In premixed phase of combustion, heat release is increased by raising compression ratio \& ethanol proportion. This heat release is also due to high volatility and low $\mathrm{CN}$. Enhanced oxygen reaction kinetics in ethanol leads to increased heat release and formation of $\mathrm{CO}_{2}$.
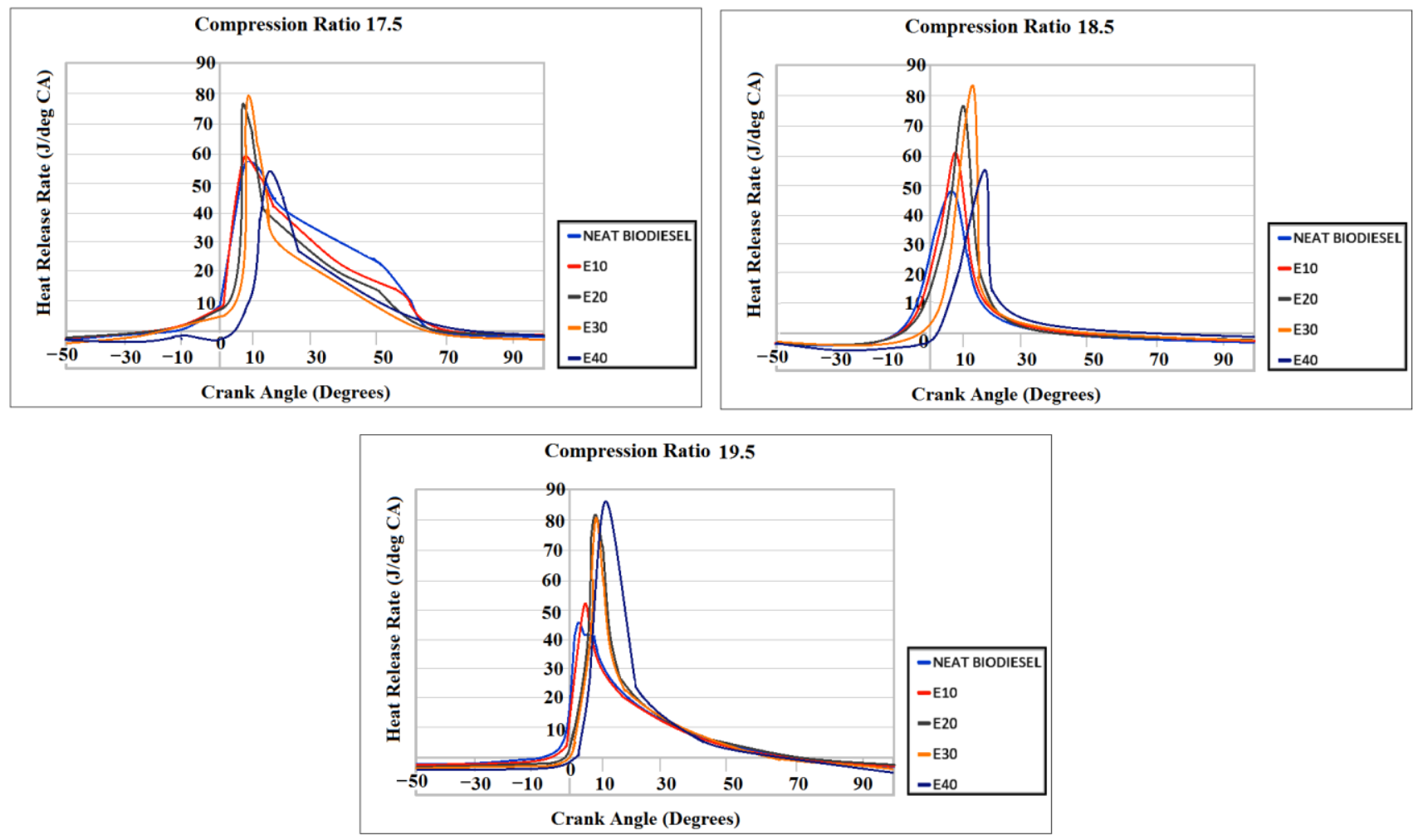

Fig.5. Comparison of Heat Release Rate with Crank Angle at various CR

\subsection{EMISSIONS}

\subsubsection{Impact on Carbon Monoxide (CO) Emission}

Fig.6. represents changes in the $\mathrm{CO}$ emissions of neat biodiesel, E10, E20, E30 and E40 at various CR. It shows that by increasing $\mathrm{CR}$ and ethanol proportion, the carbon monoxide (CO) emission decreases due to raised temperature at the end of compression stroke and change in chemical kinetics of oxygen reaction. At a particular engine load, increased percentage of ethanol proportion increases carbon monoxide emission, due to high latent heat of vaporization of ethanol which causes low combustion temperature. At high CR and at high engine load carbon monoxide decreases, due to higher affinity of carbon with oxygen caused by increased 
combustion temperature. This leads to formation of $\mathrm{CO}_{2}$ from $\mathrm{CO}$ resulting in decreased $\mathrm{CO}$ emission. At CR of 19.5:1 and at high engine load, the CO emission reduces by $10 \%, 30 \%, 15 \%$ and 5\% for E10, E20, E30 and E40 respectively when compared with neat biodiesel. But at CR of 18.5:1, under higher load, same results followed for emission of carbon monoxide however the values are comparatively higher than at CR of 19.5:1.
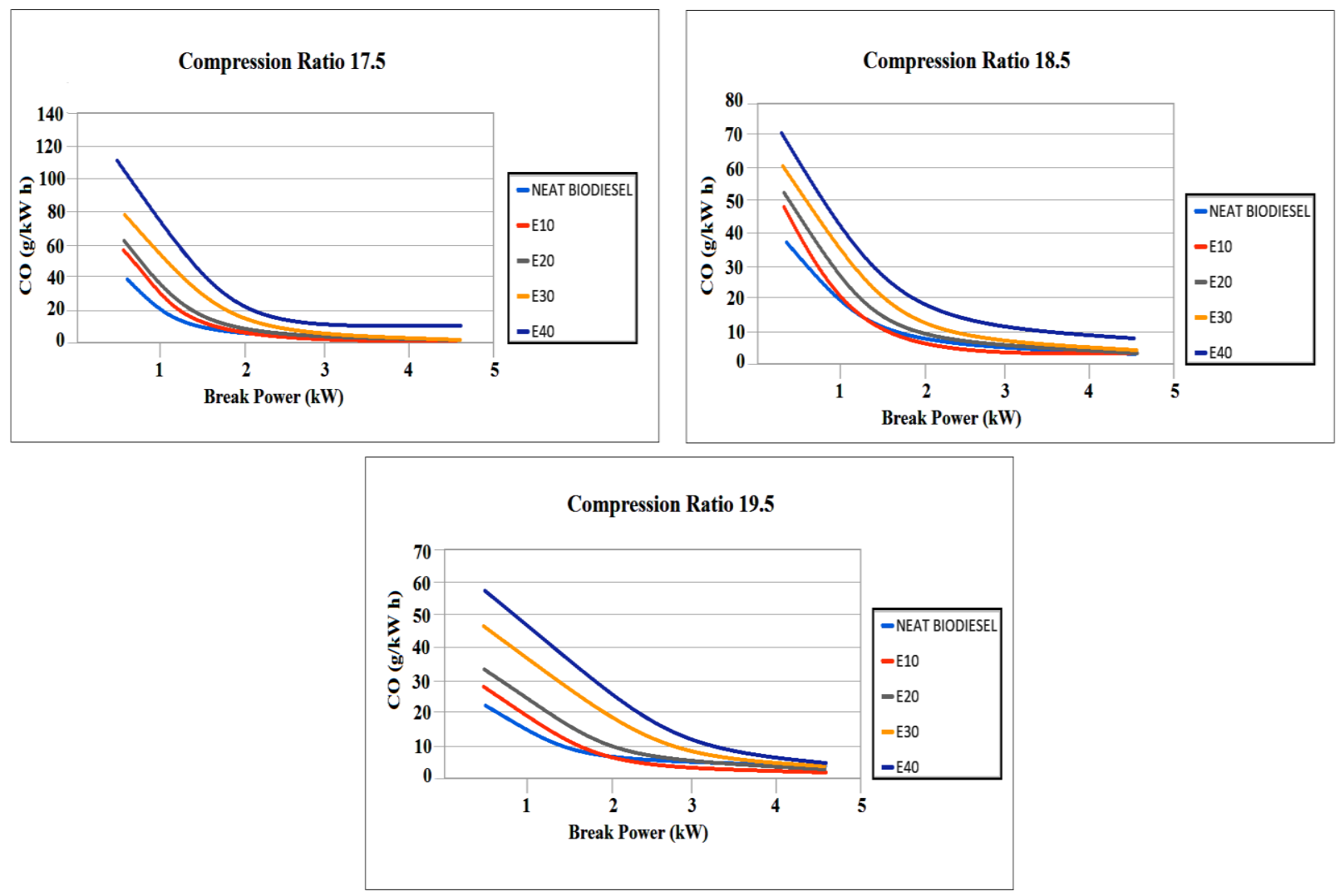

Fig.6. Comparison of carbon monoxide emission with Break Power at different CR

\subsubsection{Impact on Hydro Carbon (HC) emission}

Fig.7 represents variation of hydrocarbon (HC) emissions at various CR for neat biodiesel, E10, $\mathrm{E} 20, \mathrm{E} 30$ and E40. At low engine load, hydrocarbon emissions increase due to reduction of $\mathrm{CN}$ resulting decreased ignition delay. Increase in hydrocarbon emission by ethanol is comparatively rapid than neat biodiesel due to high latent heat of vaporization. At high CR and high engine load $\mathrm{HC}$ emission decreases, due to rapid propagation of flame and fast combustion. At high CR, hydrocarbon emissions are increased for E10 and E20 but reduced for E30 and E40. 

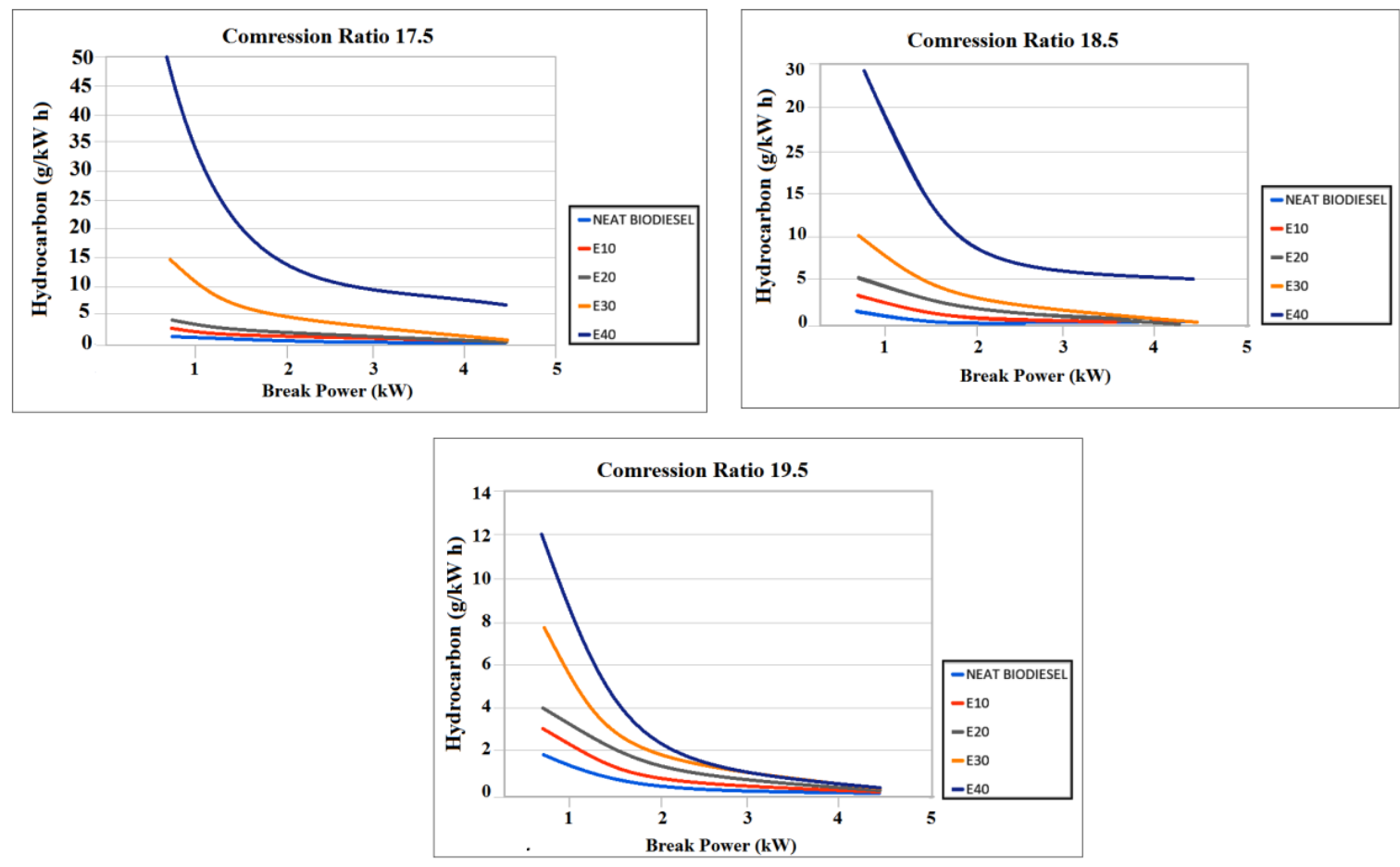

Fig.7. Comparison of Hydrocarbon Emission with Break Power at different CR

\subsubsection{Impact on Nitrogen Oxide (NOx) Emission}
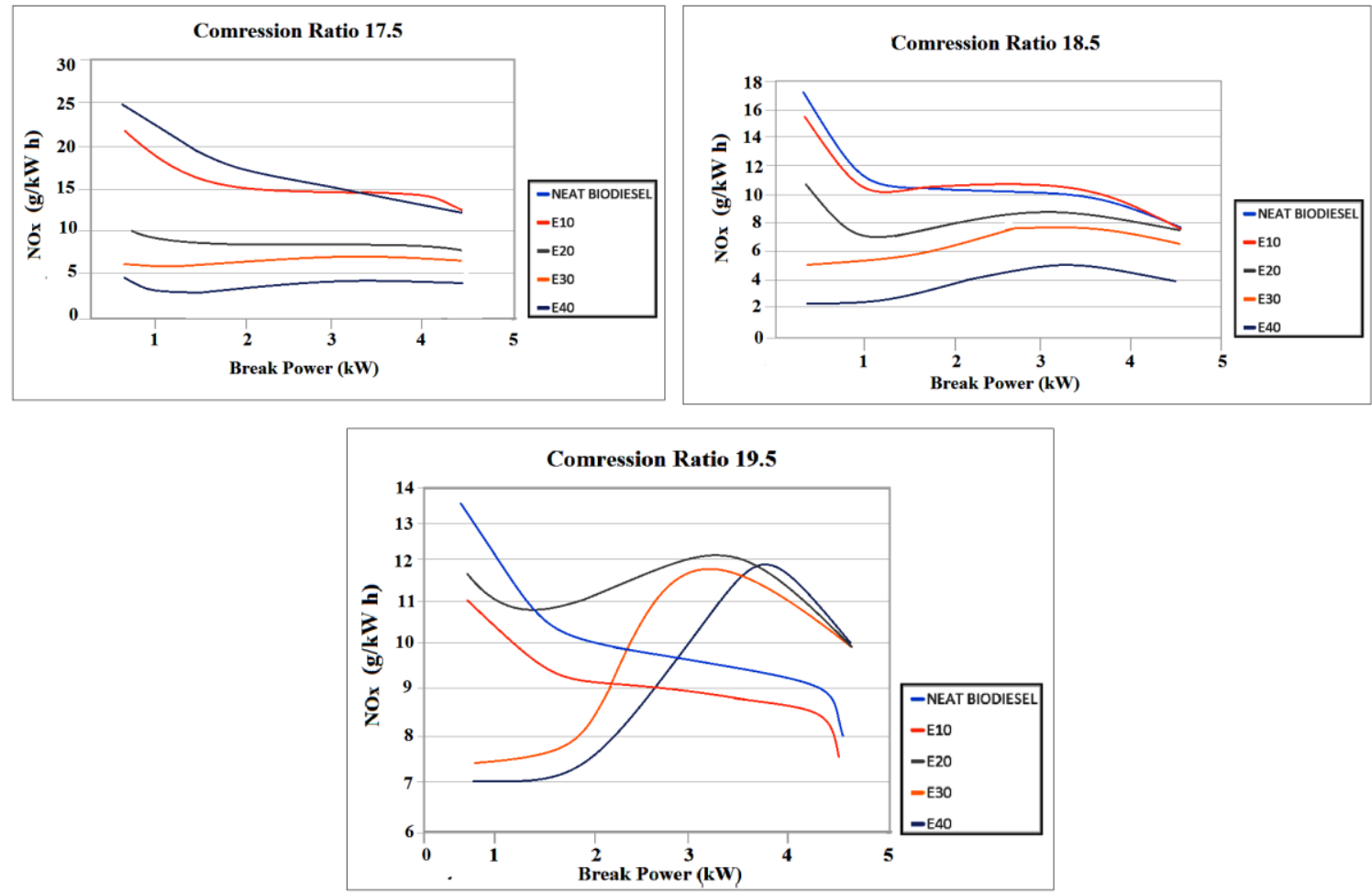

Fig.8. Comparison of Nitrogen oxide Emission with Break Power at different CR 
Fig.8. shows indicate NOx emissions increases with increasing CR and load engine. When ethanol-biodiesel blends are used in the CI engine, emissions of NOx are reduced due to the high latent heat, low latent heat of the vaporization, low cetane number and high ignition delay. Increased ethanol proportion increases $\mathrm{H} / \mathrm{C}$ ratio resulting in increased NOx emissions. Increasing the compression ratio and at high load reduce NOx for $10 \%$ ethanol and neat biodiesel due to the primary combustion resisting of the engine knock. At higher CR, NOx emissions increase by $10 \%, 12 \%$ and $40 \%$ for E20, E30 and E40 respectively.

\subsubsection{Impact on Smoke Emission}
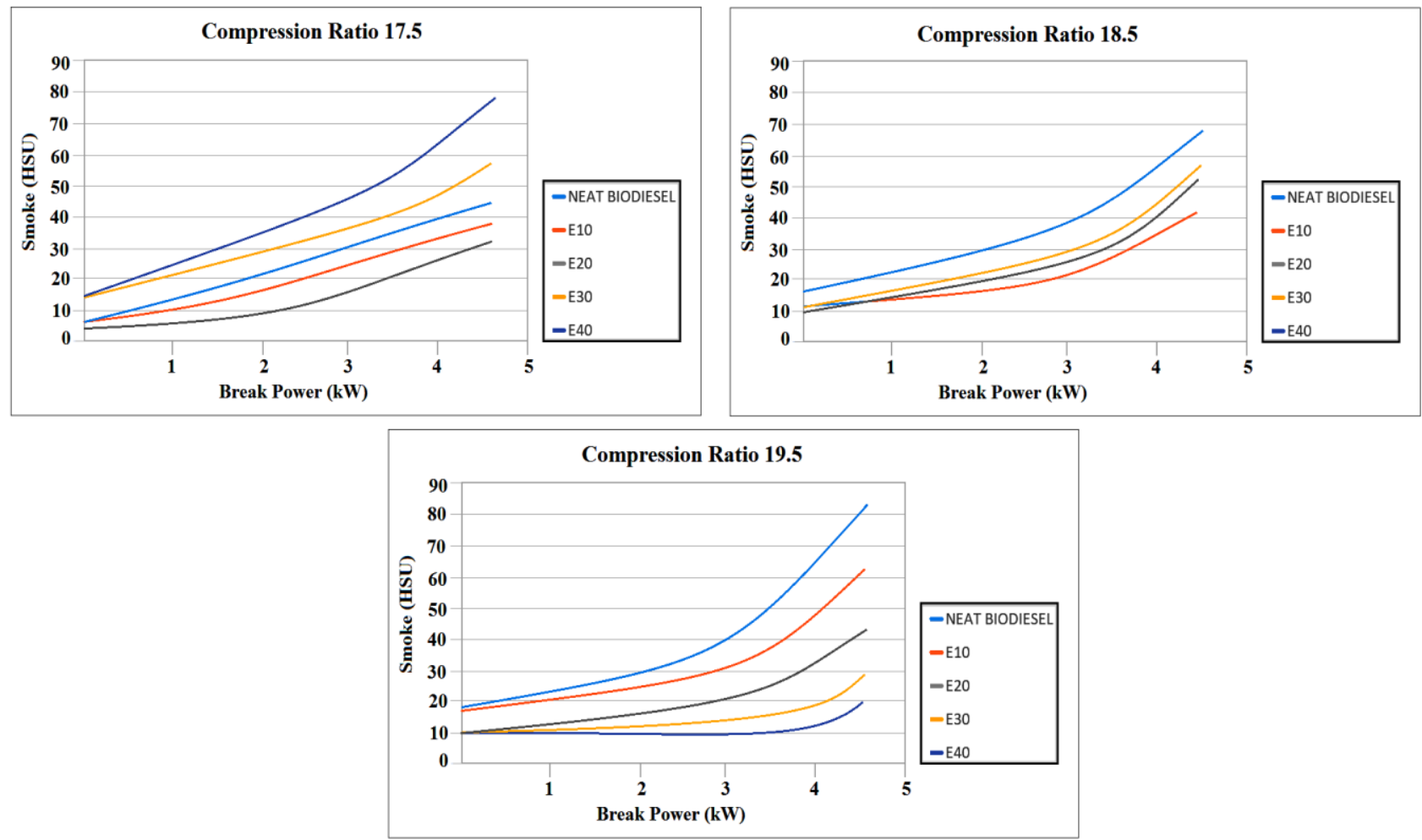

Fig.9. Comparison of Smoke Emission with Break Power at different CR

Fig.9. represents the variation in the smoke emission with the various CR, load and ethanol percentage. Ethanol blends emits comparatively less smoke than the neat biodiesel which is due to occurrence of rapid oxidation in engine cylinder caused by high oxygen content in ethanol molecular structure which results in complete burning. Generally increased load increases smoke. Increased ethanol proportion leads to longer ignition delay. 
At higher CR and at high engine load, increasing ethanol proportion leads to less smoke production due to reduced ignition delay and latent heat of vaporization. However, in lower load, increasing ethanol proportion leads to more smoke production due to increased ignition delay. Therefore, results in auto ignition occur. At higher CR and at higher load smoke reduces by $20 \%$, $15 \%, 16 \%$ and $10 \%$ for E10, E20, E30 and E40 respectively.

\section{CONCLUSIONS}

The following are findings of the various parameters like performance, combustion and emission characteristics by varying of ethanol percentage and compression ratio.

At higher compression ratio (19.5:1), break thermal efficiency (BTE) for E10 decreases and for E20, E30 and E40 increases. Increasing the ethanol percentage leads to unstable operation. At high compression ratio, ethanol also meets same pressure as compared to diesel. While increasing compression ratio upto 19.5 and higher loads, peak pressure increase upto E10, E20, E30 and then decreases for E40. At high compression ratio, due to early starting of combustion and complete burning of the fuel ethanol almost reaches the peak pressure of biodiesel though it is having low calorific value. By increasing the compression ratio to $19.5: 1$, auto ignition occurs due to lower $\mathrm{CN}$ of ethanol and higher vaporization of ethanol resulting in better fuel conversion efficiency upto E40 compared to diesel. At compression ratios of 19.5 with the various ethanol blends, heat release rate (HRR) increases gradually upto E30 but suddenly drops for E40.The heat release is also due to low $\mathrm{CN}$ and high volatility. Enhanced oxygen reaction kinetics in ethanol leads to increased heat release \& formation of $\mathrm{CO}_{2}$. Increased ethanol proportion decreases Carbon Monoxide (CO) and Hydrocarbon (HC) emission which is due to rapid mixing of ethanol and increased oxygen kinetics at high CR. At high CR and at high engine load NOx emissions decreases for neat biodiesel and $10 \%$ ethanol but thereafter increases as increasing ethanol proportion due to raised $\mathrm{H} / \mathrm{C}$ ratio. NOx emissions are comparatively higher for E40. At the lower load increasing ethanol proportion, smoke increases due to longer ignition delay. At higher compression ratio and at higher load, smoke reduces due decrease in the ignition delay. 


\section{REFERENCES}

[1]. V. Gnanamoorthi, G. Devaradjane, "Effect of compression ratio on the performance, combustion and emission of DI diesel engine fueled with ethanol-Diesel blend", Journal of the Energy Institute , 2014 PP:1-8

[2]. Keith C. Corkwell, Mitchell M. Jackson and Daniel T. Daly, "Review of Exhaust Emissions of Compression Ignition Engines Operating on E Diesel Fuel Blends", SAE International by Univ of California Berkeley, Thursday, August 02, 2018, SAE Technical Paper Series 2003-0132832003-01-3283.

[3]. Avinash Kumar Agarwal, "Biofuels (alcohols and biodiesel) applications as fuels for internal combustion engines", Progress in Energy and Combustion Science 33 (2007), PP: 233-271.

[4]. G. Amba Prasad Rao, Syed Kaleemuddin, "Development of variable timing fuel injection cam for effective abatement of diesel engine emissions", Applied Energy 88 (2011), PP: 26532662.

[5]. C. H. Lee and K. H. Lee, "An Experimental Study on the Combustion and Emission Characteristics of a Stratified Charge Compression Ignition (SCCI) Engine", Energy \& Fuels 2007, 21, PP:1901-1907.

[6]. Rajendra Pawar, Kamalesh Jagadale, Pranali Gujar, Vishal Barade, Bhushan Solankure, "A Comprehensive Review on Influence of Biodiesel and Additives on Performance and Emission of Diesel Engine”, Chemical Engineering Transactions, Vol. 65, 2018.

[7]. Magín Lapuerta , José Rodríguez-Fernández , David Fernández-Rodríguez, RaydaPatiñoCamino b, "Modeling viscosity of butanol and ethanol blends with diesel and biodiesel fuels", Fuel 199, 2017, PP:332-338.

[8]. Nadir Yilmaz, A. Burl Donaldson and Andy Johns, "Some Perspectives on Alcohol Utilization in aCompression Ignition Engine", SAE International by Birmingham City Univ, Monday, August 20, SAE Technical Paper Series 2018, 2005-01-3135.

[9]. Zhili Chen, KonnoMitsuru, "How to Put the HCCI Engine to Practical Use : Control the Ignition Timing by Compression Ratio and Increase the Power Output by Supercharge", SAE International by Univ of California Berkeley, Sunday, July 29, 2018, SAE 2003-01-1832.

[10]. Thomas W. Ryan III, Timothy J.Callahan and Darius Mehta, "HCCI in a Variable Compression Ratio Engine-Effects of Engine Variables", SAE International by University of Birmingham, August 19, 2018, SAE Technical Paper Series 2004-01-1971. 
[11]. Peng Geng, Erming C, Qinming Tan, Lijiang Wei, "Effects of alternative fuels on the combustion characteristics and emission products from diesel engines: A review", Renewable and Sustainable Energy Reviews.

[12]. Wojciech Tutak, "Bioethanol E85 as a fuel for dual fuel diesel engine", Energy Conversion and Management 86, 2014, PP: 39-48,

[13]. Wojciech Tutak, Kristóf Lukács, Stanisław Szwaja, Ákos Bereczky, “Alcohol-diesel fuel combustion in the compression ignition engine”, Fuel, 2015, No. of Pages 11, Model 5G,

[14]. A. A. Refaat, "Correlation between the chemical structure of biodiesel and its physical properties”, Int. J. Environ. Sci. Tech., 6 (4), PP; 677-694

[15]. R. Prakash, R.K. Singh, S. Murugan, "Experimental studies on combustion, performance and emission characteristics of diesel engine using different biodiesel bio oil Emulsions", Journal of the Energy Institute (2014), PP: 1-12.

[16]. Maurin Salamanca, Mauricio Velasquez, Fanor Mondrago, and Alexander Santamar' ía, "Variations of the Soot Precursors Chemical Composition Induced by Ethanol Addition to Fuel", Energy Fuels 2012, 26, PP: 6602-6611.

[17]. Xiaoye Han, Ming Zheng and Jimi Tjong "Clean combustion enabling with ethanol on a dual-fuel compression ignition engine", jer.sagepub.com at Florida International University on May 25, 2015.

[18]. Sachin Shinde, D D Palande, "Performance and Emission Analysis of Diesel-EthanolBiodiesel Blend on CI Engine-A Review", International Research Journal of Engineering and Technology (IRJET), Volume: 03 Issue: 05, May-2016, PP: 3085-88.

[19]. Madan Mohan Avulapati, Lionel Christopher Ganippa, Jun Xia, Athanasios Megaritis, "Puffing and micro-explosion of diesel-biodiesel-ethanol blends", Fuel 166 (2016), PP: 59-66, [20]. Sanjay Nagarajan, Nathan C. Skillena, John T.S. Irvineb, Linda A. Lawtonc, Peter K.J. Robertsona, "Cellulose II as bioethanol feedstock and its advantages over native cellulose", Renewable and Sustainable Energy Reviews 77 (2017), PP:182-192.

[21]. A.S.P.Vignesh, Prof C.Thamo, "Engine Performance and emission test of waste plastic pyrolysis oil, Methanol and diesel blends with a Cetane Additive AC 2010A on Four stroke twin diesel engine", International journal of engineering science invention, Volume 4, Issue 3, March 2015, PP: 01-06. 